\title{
The concise associative and dissociative dictionary as a resource for accelerated teaching of a foreign language: experimental testing of the theory
}

\author{
Nataliia Slukhai ${ }^{1}$, Liudmyla Slavova ${ }^{1, *}$, and Anastasiia Flanagan ${ }^{2}$ \\ ${ }^{1}$ Taras Shevchenko National University of Kyiv, Institute of Philology, 14 Shevchenko Blvd, 01601 Kyiv, Ukraine \\ ${ }^{2}$ Upgrades Language School, Skeppargatan 27, 11452 Stockholm, Sweden
}

\begin{abstract}
The paper outlines the results of experimental testing of the effectiveness of the principles of analogy, cognitive effects and the frame-cluster approach as a basis for a concise associative and dissociative dictionary, which is seen as a means of accelerated teaching of a foreign language based on the knowledge of the mediator language (here: English). It is a proven fact that analogy (including association) is a universal principle of thinking which enables one to correctly identify lexical units of the language of one group through the mediator. The correctness of involving the dissociative principle has been confirmed experimentally: it is based on memorizing the uncommon and different. Accelerated, interest-driven teaching of a foreign language based on associative and dissociative principles takes into account the resources of cognitive effects, which are cognitive illusions not controlled by consciousness. We have substantiated the expediency of distributing vocabulary in the proposed dictionary according to the frame-cluster principle, in which the learner constructs a situationally relevant phrase from cluster-organized associated forms. Repeated use of lexemes in communication provides a correction of errors over time. The experiment confirmed that such a dictionary can satisfy the needs of the modern information society, where multilingual communication is in demand.
\end{abstract}

\section{Introduction}

Today's information space in the context of globalisation and widespread penetration of virtual technologies is characterized by its high intensity, multisemioticity, intertextuality and collage character. The world has changed, and these changes have called forth new challenges for the information society, especially in the field of mastering foreign languages: politics, business, and the social sphere, showing, in particular, a sharp increase in the number of immigrants. Language for them is the main component in adaptation in society. Finally, cultural needs of contemporaries call for new high-speed technologies of accelerated teaching of a foreign language, corresponding to the high pace of modern life.

The purpose of the concise associative and dissociative dictionary based on the principle of analogy is to satisfy this need by providing the opportunity to master the resources minimally sufficient for communication in the private sphere in one or two weeks, and communication in fields of human activities in 3-9 weeks. The principle of analogy rests on the resources of the mediator language; thus, English can be a stepping stone to a fast and highquality teaching of other Germanic languages.
Mastering a great number of lexical units within a short period of time quickly depletes short-term memory resources; however, the support of cognitive effects (cognitive illusions) allows the learners to use the potential of suggestive learning and maintain their interest in mastering the language; ensure that a learner is "in the flow", which is defined as a state of complete involvement in the process of learning with the dominants of joyful anticipation, pleasure, full engagement (as understood by Csikszentmihalyi [1]).

In a dynamic world the passive learning of lexical units becomes an outdated practice. The concise associative and dissociative dictionary is a teaching tool based on the frame-cluster principle and pragmatically focused on the learning of vocabulary integrated into a communicative situation. Reproduction of words in the structure of repeated communicative situations will ensure the preservation of the vocabulary learned in long-term memory.

New ideas in the field of foreign language learning are promising only under the condition of experimental confirmation of theoretical constructs: the advantages and disadvantages of their implementation are noticeable only in practical application.

\footnotetext{
* Corresponding author: slavovall16@gmail.com
} 
Thus, the relevance of this research is preconditioned by the need for experimental confirmation of the possibility of high-speed situation-oriented, interest-driven foreign language learning in the context of requirements of a modern, dynamic and multicultural information society.

The purpose of the paper is to test the possibility of accelerated teaching of a foreign language involving a mediator language on the basis of using the principle of associative and dissociative teaching; activating reserves of cognitive effects; a frame-cluster approach to mastering the language.

The latest large-scale experience in successful highspeed interest-driven learning is suggestopedia as "the science of targeted use of means of suggestion in various forms and stages with pedagogically reasonable purpose, in particular for expanding the learners' mnemonic capabilities" [2, p. 5]. Suggestopedia emerged as a response to dissatisfaction with extensive methods based on training at the expense of time, involving an increasing amount of technical means and expanding training material. These methods all included the grammar and translation method of the $18^{\text {th }}$ century, the directive method of the $19^{\text {th }}$ century, Harold Palmer's method (the 20 s and $40 \mathrm{~s}$ of the $20^{\text {th }}$ century), the audio-lingual method (Ch. Fries, R. Lado, the 1940s and 60s), the audiovisual method (P. Gouberina, P. Rivenc, the 1940s and 1960s). Suggestopedia generated intensive methods which are based on acceleration of learning per time unit due to the appeal to the reserve mental resources of a person. Broadly defined, suggestopedia is based upon the use of natural suggestion resources as a manifestation of spontaneous speech communication ("Silent Way" of Caleb Gattegno; "Natural approach" presented in works of Stephen D. Krashen and Tracy Teller (its variety became the method of Total Physical Response, known as J. Usher's method), drama pedagogy, "Situational Language Learning"; Hi TECH; the project or case method described by J. Dewey and W.H. Kilpatrick; the tandem method). In a narrower sense, suggestopedia is based on the use of suggestion resources outside the rational control of a person (this is the suggestive method of Georgi Lozanov and the emotional semantic method of Galyna Kitaygorodskaya, the method of verbal image emotional-volitional control of a person's state (Georgiy Sytin); the suggestocybernetic training method after Viacheslav Petrusinskii; but also hypnopedia, rhythmopedia, relaxopedia, Freire pedagogy and others. All these methods are based on the cognitive approach to language and human thinking (the history of suggestopedia is fully considered in [3, pp. 170-183]). All these methods rely on teaching by using a typical or atypical dictionary either encyclopedic or linguistic - dictionary as an extract of speech or "dissolved" in a discourse, visualized or sounding, curtailed to "dots" of a consciously unconscious associative-verbal network or expanded and emotionally expressively enhanced dictionary, suggested or imposed onto the mind, with the added possibility of it assuming a virtual form.
The history of dictionary making relevant to foreign language learning abounds in promising solutions, as does the history of the above-mentioned training methods. There are different types of dictionaries compiled in order to satisfy various needs. Dictionaries assist users to achieve a set of goals; correspondingly, there are distinguished: encyclopedic dictionaries; etymological dictionaries; monolingual dictionaries; bilingual dictionaries; thematic dictionaries; spelling dictionaries; terminological dictionaries, etc. Among monolingual, bilingual, and multilingual dictionaries the most widelyspread are bilingual ones.

The most typical reason for consulting a dictionary is finding out what a word means. In this case, bilingual or explanatory dictionaries are used. In bilingual dictionaries the source language is a foreign one for the user and the target language can be either the user's native one (or the one better known in comparison with the source language) [4]. In such type of dictionaries we are supposed to find the meaning of the source language entry. L.V. Ščerba differentiated between a translation dictionary and an explanatory dictionary, arguing in favour of the latter [5].

The main idea of a bilingual dictionary is to provide a perfect target language equivalent for each source language headword. The classification of equivalents (cognitive, translational, explanatory, and functional) was described in works of Zgusta [6], Adamska-Sałaciak [7, 8], etc.

At the end of the twentieth and the beginning of the twenty-first century there was observed a tendency in the sphere of dictionary compiling from introspection-based to corpus-based. Mainly electronic corpora (e.g. Sketch Engine, Mova.info, etc.) have been involved. Online bilingual dictionaries are gaining popularity, and new lexicographic projects appear, e.g. Norwegian and Swedish Lexin project, French Dictionnaire ARTES project. The tendency of applying information technologies has also been traced in Slavic lexicography [9, 10, 11, 12, 13, etc.].

Bilingual dictionaries differ in number and type of items included, amount of information in a single headword, and the target audience. The last factor predetermines the scope and directionality of a dictionary [14].

We'd like to focus our attention on bilingual dictionaries serving educational purposes, i.e. bilingual learners' dictionaries $[15,16,17,18$, etc.]. They are suitable for learners of all levels: from beginners to advanced students. The role of dictionaries in the process of learning a foreign language cannot be overestimated. The idea is to suggest a relevant dictionary that will facilitate that process.

Zöfgen writes, "It is therefore all the more surprising that in a market saturated with language learning material a bilingual dictionary developed along the lines of pedagogical lexicography and especially designed for the foreign learner is [...] still not available" [18, p. 2888].

Intensive learning of a foreign language is possible if the cognitive approach is applied, the so-called cognitive 
effects are involved [19]. There has already been a successful attempt to compile the Associative Thesaurus of English [20]; The Edinburg Associative Thesaurus and the Associative Thesauri of Russian and English languages based on a psychological perception of consciousness units linked in the human psyche [21].

As for the present situation with the bilingual learners' dictionaries, it is quite vivid that there is practically a small variety of dictionaries that can boost the learning process. There is an urgent need in bilingual dictionaries specially designed for learners, especially those who learn other kindred languages like English, Swedish, and German.

If comparison of languages at the stage of their development is typology, then at the stage of their perfection it is primarily comparison of their pictures of the world created with the help of languages [22, p. 66].

It is necessary to bring truly innovative approaches into the vast field of dictionary-making.

The intensification and complication of the information flow of modern civilization requires finding new principles and teaching methods, offering new types of dictionaries in order to simplify and speed up teaching.

The concise associative and dissociative dictionary we offer as a resource for accelerated teaching of a foreign language is suitable for learners with good knowledge of the mediator language and is governed by three principles: using the capabilities of associative and dissociative thinking; reserves of cognitive effects; and the distribution of lexis among frame clusters simulating simple communicative situations ("I buy bread" is made up of the subject, action, object clusters). Swedish has been chosen as the language to be learned. With over 9 million speakers it is the most popular Germanic language spoken in Scandinavia, it is quite relevant to use the associative and dissociative method to master this language. English is chosen as the mediator language with a view to its global status with the highest percentage of speakers in the world.

The associative and dissociative principle is based on unequal components: the associative principle dominates as a reflection of the universal law of analogy. Analogue thinking is both the product and the tool of human social development. It is as old as society that has realized its human nature. Fundamental analogy is a consistent property of consciousness [23], i.e., after M. Heidegger, "analogy, understood as the main feature of being, outlines completely certain possibilities and ways of producing the truth of this being inside existence "correspondence, thought, as the fundamental characteristics of the Being of whatever is, furnishes the pattern for very specific possibilities and modes of setting the truth of this Being, in whatever has being, into the work" [24, p. 143]. Thus, analogy is characteristic of speech activity and can be observed on all levels of the language structure. The logic and linguistic content of the analogy axis is the relationship of identity (including pseudo-identity), similarity, analogy proper and close or remote association. The midpoint of the axis is constituted by the logical linguistic relations of similarity, but that is only by convention, since any point on the axis may occupy a central position depending on the focus of attention. Therefore, the analogy axis may also be called the axis of similarity, identity or association (explained by N. Slukhai [25, pp. 260-264]).

Dissociative thinking, which mirrors the associative, is helpful for memorizing. Lexemes chosen on the basis of dissociation should take up to ten times less volume in the learner's dictionary and to the highest degree meet the principle of dissimilarity and even exotic character for the learner's linguistic consciousness; they must evoke great interest and be placed in the von Restorff cognitive effect zone, as one exploits the cognitive effect reserve of the unusual, different from the norm, interesting, and exotic.

Cognitive effects are a by-product of human creative thinking. They allow using resources of the subconscious, not controlled by the mind; opening up the resources of cognitive zones that are not covered by rational thinking. The role of cognitive effects, such as distortions and illusions, in associative and dissociative teaching can hardly be overestimated; the algorithm of these effects is described in [19].

The frame principle of organizing the material allows the learner to quickly get the pragmatic effect of language proficiency. It is well known that grammar in the human mind is lexicized, it is represented by words that appear in "pre-speech readiness". This makes it possible to easily place analogue forms in the utterance structure, reflecting the typical frame structure. Modern thinking is highly anthropocentric, placing the "I" in the subject actant position of the frame, we assume after mentioning the action ("want") and a range of objects ("bread, butter, milk"), which are easy to memorize when placed in a typical frame position. The best way to learn vocabulary is when a lexical unit is related to a given frame. Such an approach enables a learner to retain words in long-term memory. The idea that the meaning of words is best characterized in terms of experience-based schematization of events and objects in the speaker's world [26, p. 1320] has been proved in the FrameNet project operated by the International Computer Science Institute (Berkeley, the USA). It brings pleasure to learners when they can use language in basic situations, even if it is just the result of the cognitive effect of surface knowledge (the DunningKruger effect). Maintaining interest in a language and being able to see one's own progress facilitate further learning and help quickly achieve basic proficiency.

The theory of accelerated teaching of a foreign language with the help of a concise associative and dissociative dictionary has been substantiated [19], and applied in a teaching practice. However, it still needs experimental verification. Any theory supported by experiments turns out to be an important step either in confirmation or rejection of its outcomes. But as practice shows, experiments usually prove its efficiency. The theory of frame semantics has been applied to the 
construction of the online Multimedia Encyclopedia of Japanese Mimetics [27]. The results of the experiment proved the efficiency of the frame-semantic approach to mimetic semantics.

An experimental verification of these provisions is presented in the results of this paper.

\section{Methodology}

Material of the research consists of the following experimental data: 56 extended questionnaires based on the language material of the sample in the amount of more than 3,000 lexemes from the online resource hosgeldi.com ("The Swedish language: lessons"), reduced to about 1000 lexemes of the concise associative and dissociative dictionary. The main method is experiment, supplemented by cognitive analysis, the ranking of lexemes according to associative and dissociative principles, degree of usage in speech, frame and qualitative characteristics; observation and description.

A free associative experiment was conducted in student groups majoring in translation (translation from English and other Western European languages) in their $3^{\text {rd }}$ or $4^{\text {th }}$ year of the Bachelor's program or $1^{\text {st }}$ and $2^{\text {nd }}$ year of the Master's program. The experiment was carried out at the Institute of Philology, Taras Shevchenko National University of Kyiv, from November 10 to December 10, 2019. The number of students is 56. The number of responses received to each question varied between 47 and 56.

The aim of the experiment was to establish whether the principle of associative and dissociative teaching has any effect on accelerated learning of the language, and if so, then to what extent and in which groups of lexemes; whether cognitive effects are effective (based on one: the von Restorff effect); and whether the frame-cluster distribution of material influences the process of memorizing the words.

The associative experiment was carried out in the form of a questionnaire; the duration of the experiment was limited to two academic hours.

The questionnaire included two batteries of questions. The first dealt with some identifiers of the linguistic personality and potential linguistic competence of students (1. Your age and gender. 2. Level of English proficiency; 3. How long have you been learning English? 4. What other European languages are you proficient in?).

The second battery of questions concerned the identification of resources and the influence of associative and dissociative thinking of students; cognitive effects and the frame-cluster distribution of words to help students in their accelerated learning of Swedish with English as the mediator language.

Two batteries of questions were given to students, whose proficiency in English was at the level of upperintermediate. Such level of proficiency allows identifying based on the method of analogy on average $37 \%$ of the lexemes randomly offered by the electronic resource of the website www.hosgeldi.com. However, the analogy fixed in consciousness between the lexemes of the Swedish and English languages has different degrees of manifestation, which was shown by the test data in the questionnaires.

Carrying out the experiment among the students, the authors of this technique deliberately left out of sight a great number of lexemes which pose zero translation difficulty with a high level of coincidence of the form and meaning of correlative lexemes (att kopiera, att decorera, att dansa, att notera, att spendera, att reparera). It is obvious that there is no difficulty in translating them; the number of these lexemes reaches $10 \%$ of the virtual source dictionary.

The associative thinking of students was measured by tasks for translation from the unfamiliar language (Swedish) into English (language proficiency is not lower than Intermediate). The translation was expected to be made on the basis of association by form and place in the analogy paradigm, the inner form (image).

Tasks of low, medium and high difficulty were proposed. For example, the lexemes att hata, att sitta, att gå upp, att landa, att sälja were placed in the low translation difficulty level. The lexemes of low difficulty were distributed according to the frame positions of subject, object, action/state, instrument, time, space, number, color $\left(1^{\text {st }}\right.$ column) or not distributed (the $2^{\text {nd }}$ column). The aim was to establish whether the identified position of the lexeme in the frame structure makes the analogue translation easier, e.g., subjects: jag, en man, en son, en dotter, en bror; objects: bröd, mjölk, ett misstag, en vinge, ett bröst; actions: att gå, att komma, att höra, att svälja, att ha; states: livlig, arg, törstig, drucken, trött; instruments: en panna, en hammare, en kniv, en yxa, en maskin; time: morgon, nu, en dag, efter, en natt; space: här, nära, Syd, Väst, en ocean; number: få, en, två, tre, fyra; color: röd, grön, blå, vit, grå.

In the next task the students were encouraged to translate vocabulary with the low degree of difficulty, not arranged by clusters: att förbjuda, att dricka, att möta, att bita, att blåsa, att glida and the like.

In the task of the medium level of difficulty there were offered lexemes that were not distributed according to frame position (correlating with similar ones in the previous task with lexemes of the low level of difficulty of identification, lexemes of medium level of difficulty of analogue translation demonstrate the depth of human analogue thinking), e.g. att kyssa, att slicka, att följa, att ljuga, att viska.

The task of a high level of difficulty contains lexemes that are difficult to identify in the analogue paradigm, i.e. those that are not suitable for the associative teaching methods. Lexemes that are difficult to identify include those ones the interpretation of which requires special knowledge, though their analogue potential is quite high: att möta (to meet), att låta (to let), att tro (to trust). 


\section{Research results}

The analysis of the answers given by the students has allowed us to establish the following correlations: the depth of associative and dissociative thinking does not depend on age or gender but does depend on the level of English proficiency (it was easier to detect analogue connections for those who had Upper Intermediate or higher). In the case of Swedish, it also depends on knowledge of other Germanic languages (in particular, it is productive to know both English and German; while knowledge of Romance languages does not influence the successful search for analogue connections).

Lexemes which had been sorted by clusters according to typical frame positioning were translated more successfully than those that had not been sorted (see Fig. 1).

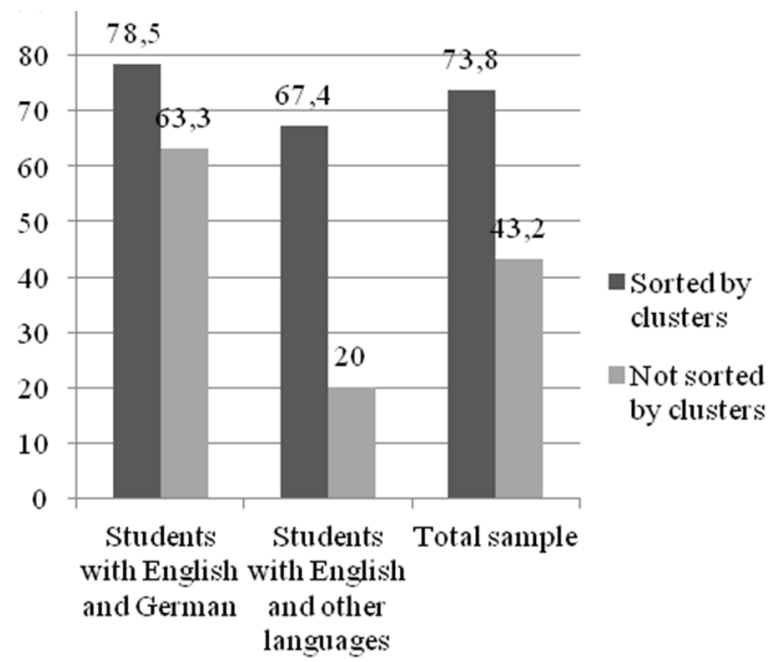

Fig. 1. The difference in translation done by: all students; those who know English and German; those who know English and other languages (except German), of analogue forms of low degree of translation difficulty sorted by clusters and not.

As it was expected, students translated lexical units displaying a high and medium degree of analogy, i.e. a low degree of translation difficulty (combined when calculating) more successfully than lexical units with a low degree of analogy. The correlation between proficiency in various languages and the rate of correct answers was as described (see Fig. 2).

Students' dissociative thinking was measured by two tasks: to translate lexemes with a high level of identification difficulty (i.e. the low level of associativity mentioned above) and to translate lexemes not distributed in the frame structure, indicating ethnically relevant phenomena that usually cause increased interest in studying the language: Midsommar - Midsummer, Jul Christmas, Nyår - New Year, Kanelbullens dag Cinnamon Bun's Day, fikastund - coffee break, Tjugondag Knut - St Knut's day, Alla Helgons Dag - All Saints' Day, sambo - cohabiting partner, särbo - partner but living apart (the words were given without translation).

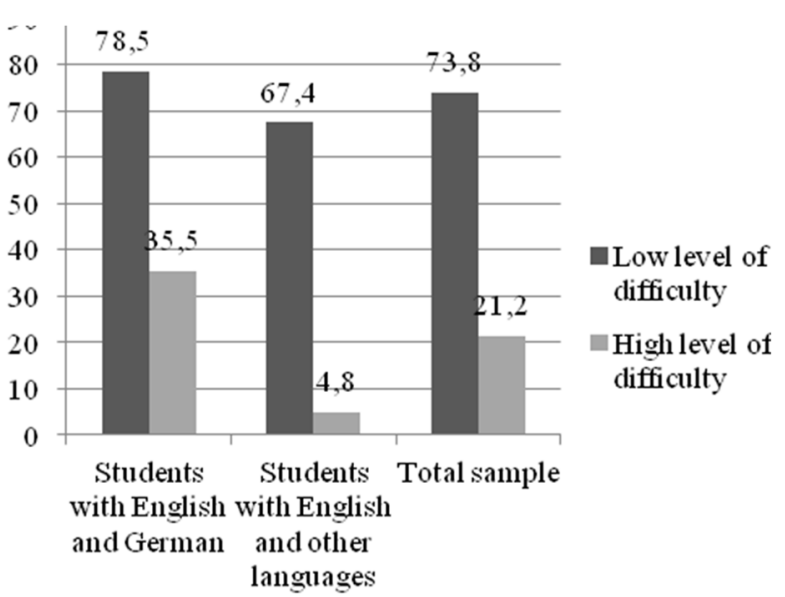

Fig. 2. Comprehension of low difficulty word sets versus high difficulty ones with words grouped by clusters (per cent)

They include lexical units of ethnoculturally relevant phenomena (modern and historical, profane and sacral), ethnoexotisms, including an unusual visual form (mormor - maternal grandmother) or their sounding (Hur mår du? How are you? including homophones: sex - six, bra good) and ethno-culturally resonant deviations concerning average regional norms, and not necessarily negative (nusvenskar - new Swedes). The level of difficulty of the task (in relation to the answers received) was rated by students as 4.1 (on a scale from 1 to 5). The level of difficulty in perceiving the words of a dissociative block (lexemes of a high level of difficulty in translation and ethnoculturally relevant lexemes) in connection with the range of learned languages is displayed in Figure 3.

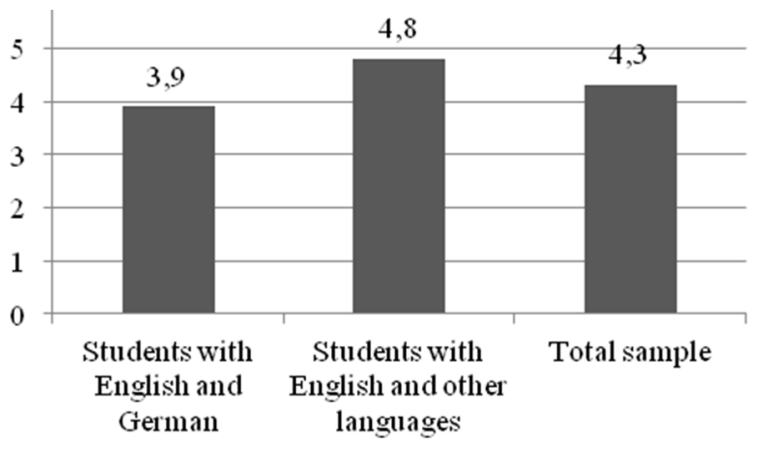

Fig. 3. The level of difficulty while perceiving words of the dissociative group by all students; students with competence in English and German; in English and languages other than German (in points on a scale of 1 to 5).

The dissociative group as a rule includes ethnoculturally relevant lexemes which usually elicit increased interest among recipients of the new culture and 
are usually perceived differently from non-transparent dissociative lexical units.

They are expectedly difficult to understand (see Figure 4). However, they attract special attention of students interested in understanding a new linguoculture. Accordingly, the aim of the next task was to establish if it is possible to use the increased interest of students in mastering ethnocultrally relevant information to accelerate learning. When presenting a translation followed by explanations of ethnoculturally relevant information, students displayed a higher degree of involvement and easily reproduced the meanings of lexemes when asked during the follow-up assessment a week later. To assess the success of dissociative training students were also asked to answer the question whether it was fun and interesting to translate ethnically relevant lexemes, and if so, to give the reason (the aim of the task was to find out whether the von Restorff cognitive effect works in the field of teaching a foreign language; or the isolation effect, which makes the different element in a range of more similar ones easier to memorize [3]). The answers were the following: yes (without explanation - 7); yes, because it is fun and informative; because it is unusual due to belonging to a different culture while denoting something familiar; because it is a different designation within the Germanic group; it is extremely interesting because it activates associative thinking and causes one to look for hidden regularities in the lexical system; it is very interesting to face the "dissociative challenges"; it brings satisfaction when you give a correct answer; it is exciting to translate ethnically relevant lexemes; it is always exciting to implement knowledge in new fields; it is truly enticing because it challenges your knowledge and logic; it is fun to look for the inner form of the words; difficult but interesting because it activates translation skills, because it widens your horizon and enriches your background knowledge in culture; it is interesting to compare the degree of similarity between English and Swedish words; it is interesting to find associations based on knowledge of other known languages. However, there were answers 'no' that amounted to $8 \%$ (it does not provide ground for the development of linguistic intuition; it is difficult; complicated because it is not possible to see correspondence; lack of knowledge is not compensated by the associations). Presumably the efficiency of cognitive effects while studying the dissociative layer of lexical units will increase if the visual representation of the image is provided: this task is easily solved in a digital version of the associative and dissociative dictionary.

In the questionnaire the students were also asked to find an explanation for their ability to translate the words of the unknown language. As a hint students were offered three answers: the form, the inner form of the word, and attraction of analogue paradigm (rated on an ascending scale from 1 to 5). At the same time, the form (basically connected with the meaning) and the attraction of the analogue paradigm, presented to students as two answer options, in fact, demonstrate one phenomenon.

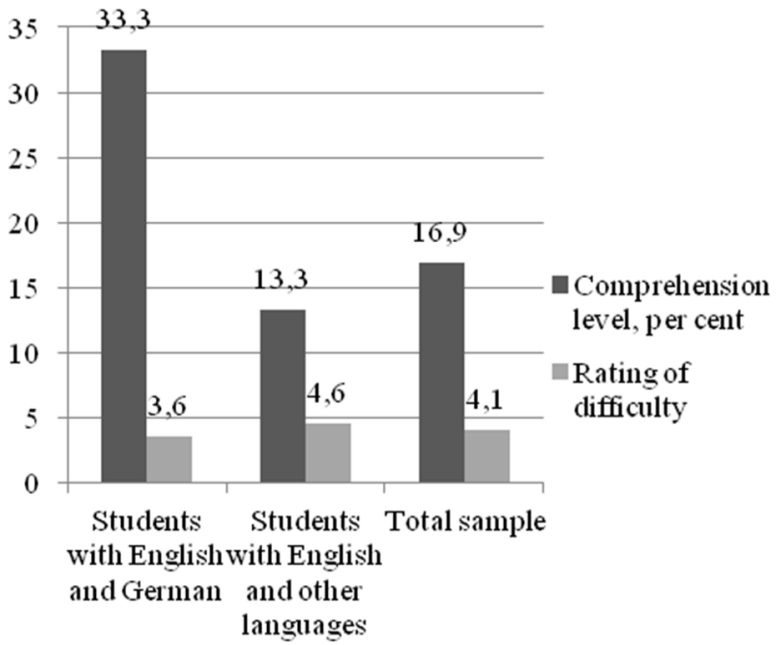

Fig. 4. Comprehension of the ethnic relevant lexics.

The total number of points for "the form" is 147 , for "the inner form" - 134 and "attraction of the analogue paradigm" - 207. These results demonstrate the students' awareness of the impact of analogue paradigm. Qualitative results are even more revealing: the maximum influence of the analogue paradigm (rated with 5 points) was indicated by 41 out of 56 students; the maximum importance of the form was perceived by 5 students; the maximum importance of the inner form was indicated by only 4 students; others found it difficult to answer. The qualitative results of these responses are correlated with the qualitative results of training students majoring in this specialty, which is likely to indicate that the higher the students' linguistic competence, the higher their orientation potential in the analogue paradigm. However, taking into account that only 4 students rated the influence of the analogue paradigm with two points, and only three students gave one, it can be argued that almost all students are aware of the high influence of the analogue paradigm.

The next task was to transcribe 5 lexemes that were easily visually identifiable, but difficult audibly, all supplied with translations: att gäspa - to gape, att sjunga to sing, tjock - thick, fat; att knäfalla - to kneel, ett hus - a house. The purpose here was to determine whether the visual analogue paradigm indeed plays a leading role in accelerated language learning, and losses in the communication channel with distorted speech production should be recognized as acceptable. As expected, students transcribed the words with distortions of the sound image, to a greater or lesser extent they resembled sounding of English words (like ett hus - at ys; att gäspa - at gaspo (sic), etc.). However, the sound image of a word reproduced by an inexperienced speaker with distortions will still be adequately perceived by an experienced speaker. Several attempts to pronounce the word or form 
with distortions and subsequent external corrections will help come to the correct pronunciation according to the rules; however, these losses in communication might be viewed as acceptable in view of the significant gains in terms of accelerated language learning.

\section{Conclusions}

Thus, the experiment confirmed the potential of the concise associative and dissociative dictionary as a method for accelerated foreign language teaching with reference to the mediator language, namely: the correctness of reliance on analogue (associative) forms of low and medium levels of perception difficulty (a zero level of perception difficulty will bring definitely positive results); the relevance of involving dissociated forms when it comes to ethnically relevant phenomena that cause obvious interest; the effectiveness of cognitive effects; efficiency of lexical units distribution in an associative and dissociative dictionary according to the frame-cluster principle. In this case, both digital and printed versions of the associative and dissociative dictionary are better to compile according to clusters, enabling the learner to build situationally relevant utterances out of the associative forms: Jag vill äta; Jag vill ha en röd hatt; Jag måste köpa bröd och mjölk; Jag vill ha en kopp kaffe; Jag måste gå; Ge mig bröd och fisk. Any English-speaking person can build these phrases having the associative and dissociative dictionary, which determines the prospects of this project. It is advisable to supplement the digital version with visual images of ethnically relevant phenomena.

Based on the results of the experiment, however, the following drawbacks of the proposed dictionary can be predicted:

1 Accelerated language learning with the help of a concise associative and dissociative dictionary requires knowledge of the mediator language at the level of upper-intermediate (preferably two languages).

2. The part of the dictionary that will be learnt will correspond to a strong anthropocentric regulator, placing the main emphasis on daily language and, partly on media and arts spheres, but will be much less relevant for professional communication.

3. Only part of the dictionary subordinated to the associative and dissociative principle can be mastered and practically applied due to the suggested technique, i.e. less than $50 \%$.

4. It can be assumed that there will occur distortions in the pronunciation of separate sounds or parts of words until they are situationally corrected.

5. There can also be some grammatical distortions, which will be corrected in spontaneous communication.

Despite these restrictions, it has been experimentally confirmed that a concise associative and dissociative dictionary as a resource for accelerated teaching of a foreign language is able to satisfy the needs of today's information society, where there is an acute demand for personal multilingual communication.

\section{References}

1. M. Csikszentmihalyi, Flow: The Psychology of Optimal Experience (Harper and Row, New York, 1990)

2. S.S. Palchevskii, Dissertation, Institute of Pedagogy of National Academy of Pedagogical Sciences of Ukraine, 2003

3. N.V. Slukhai, Suggestiya $i$ kommunikatsiya: lingvisticheskoye programmirovaniye povedeniya cheloveka (Suggestion and communication: linguistic programming of human behavior). (Kyiv National University Press, Kyiv, 2012).

4. A. Adamska-Sałaciak. In International Handbook of Modern Lexis and Lexicography, ed. by P. Hanks, J.M. de Schryver (Springer, Berlin, Heidelberg, 2015). doi:10.1007/978-3-642-45369-4_6-2

5. L. Ščerba, Towards a general theory of lexicography (trans: Farina, D.). Inter. J. Lexic. 8(4), 305-349 (1995). doi:10.1093/ij1/8.4.314

6. L. Zgusta, Manual of lexicography (Academia, Prague; Mouton, The Hague, 1971)

7. A. Adamska-Sałaciak, Meaning and the bilingual dictionary: The case of English and Polish (Peter Lang, Frankfurt-am-Main, 2006)

8. A. Adamska-Sałaciak, Examining equivalence. Inter. J. Lexic. 23(4), 387-409 (2010). doi:10.1093/ij1/ecq024

9. M. Banko, $Z$ pogranicza leksykografii $i$ językoznawstwa (On the borderline of lexicography and language study). (Wydzial polonistyky UW, Warszawa, 2001)

10. P. Zmigrodzki, Wprowadzenie do leksykografii polskiej (Introduction to Polish lexicography). (Wydawnictwo Uniwersitety Śląskiego, Katowice, 2009)

11. V.A. Shyrokov, Linhvistychni ta tekhnolohichni osnovy tlumachnoyi leksykohrafiyi (Linguistic and technological basis of interpretative lexicography). (Dovira, Kyiv, 2010)

12. V.A. Shyrokov, Kompiuterna leksykohrafiya (Computer lexicography). (Naukova dumka, Kyiv, 2011)

13. Z. Saloni, Perspektywy polskiej leksykografii jednojęzycznej (Outlook of Polish monolingual lexicography). Poradnik językowy 7, 1-18 (1996)

14. A. Adamska-Sałaciak, In The Bloomsbury companion to lexicography, ed. by $\mathrm{H}$. Jackson (Bloomsbury Academic, London, 2013), pp. 213-231

15. A. Adamska-Sałaciak, in English Learners' Dictionaries at the DSNA 2009, ed. by I.J. Kernerman, P. Bogaards (K Dictionaries, Tel Aviv, 2010), pp. 121-137 
16. R.H. Gouws, Monolingual and bilingual learners' dictionaries. Lexikos 14, 264-274 (2004)

17. J. Tomaszczyk, In Lexicography: principles and practice, ed. by R.R.K. Hartmann (Academic Press, London, 1983), pp. 41-51

18. E. Zöfgen, in Dictionaries: an international encyclopedia of lexicography, ed. by F.J. Hausmann et al., vol. 3 (Walter de Gruyter, Berlin, New York, 1991), pp. 2888-2908

19. N. Slukhai, S. Slukhai, A. Flanagan, Kognitivnyye effekty kak resurs analogovogo obucheniya: printsipy sozdaniya assotsiativno-dissotsiativnogo slovarya (Cognitive effects as a resource for analog learning: principles for creating an associative-dissociative dictionary). Science and education: a new dimension. Philology VII(62), I. 211, 49-53 (2019)

20. G. Kiss, An associative thesaurus of English (University of Edinburg, Edinburg, 1972)

21. N. V. Ufimtseva, The associative dictionary as a model of the linguistic picture of the world. Procedia Soc. Behav. Sc. 154, 36-43 (2014). doi:10.1016/j.sbspro.2014.10.108

22. V. M. Alpatov, Istoriya lingvisticheskikh ucheniy (History of Linguistic Doctrines). (Jazyki slavjanskoj kultury, Moscow, 2005)

23. O.O. Taranenko, Polisemichnyy paralelizm $i$ yavyshche semantychnoyi analohiyi (Polysemic parallelity and semantic analogy). (Naukova dumka, Kyiv, 1980)

24. M. Heidegger, The questions concerning technology and other essays (Harper Perennial, New York, 1977)

25. N. Slukhai, Dissertation, Taras Shevchenko National University of Kyiv, 1996

26. Recent developments with focus on electronic and computational lexicography, ed. by R.H. Gouws, U. Heid, W. Schweickard, H. E. Wiegand. Dictionaries. An international encyclopedia of lexicography. Suppl. vol. (Mouton De Gruyter, Berlin, 2013).

27. K. Akita, in Cognitive-functional approaches to the study of Japanese as a second language, ed. by K. Kabata, K. Toratani (Mouton De Gruyter, Berlin, 2016), pp. 139-168 